\title{
Influence of Anti-Glaucoma Drugs on Uptake of Extracellular Vesicles by Trabecular Meshwork Cells
}

This article was published in the following Dove Press journal:

International Journal of Nanomedicine

Saray Tabak

Sofia Schreiber-Avissar

Elie Beit-Yannai (iD

Clinical Biochemistry and Pharmacology Department, Ben-Gurion University of the Negev, Beer-Sheva, Israel
Correspondence: Elie Beit-Yannai

Clinical Biochemistry and Pharmacology Department, Ben-Gurion University of the Negev, POB 653, Beer-Sheva, 84I05, Israel

Tel +972-8-6477374

Fax +972-8-6479303

Email bye@bgu.ac.il
Background: Extracellular vesicles (EVs) are capable of manipulating cellular functions for the maintenance of biological homeostasis and disease progression, such as in glaucoma disease. These nano-particles carry a net negative surface charge under physiological conditions that can contribute to EVs:EVs interaction and their uptake by target cells.

Purpose: To investigate the effect of glaucoma drugs on EVs physicochemical characters and the implications for their uptake by trabecular meshwork (TM) cells.

Methods: TM or non-pigmented ciliary epithelium (NPCE) cells derived EVs were incubated with commercial anti-glaucoma formulation, Timolol maleate, Brinzolamide or Benzalkonium $\mathrm{Cl}$ and their size and zeta potential (ZP) and physical interactions of EVs derived from NPCE cells and TM cells were evaluated. The contribution of EVs interactions to up-take by TM cells was examined using fluorescence-activated cell sorting.

Results: EVs size and ZP were affected by the ionic strength of the buffer rather than EVs type. Commercial glaucoma eye drops, including $\beta$-blocker, $\alpha$-2-agonist and prostaglandin analogs, reduced NPCE EVs ZP, whereas exposure of EVs to carbonic anhydrase inhibitor caused an increase in the ZP. A correlation was found between increased ZP values and increased NPCE EVs uptake by TM cells. We were able to show that Benzalkonium chloride stands behind this ZP effect and not Timolol or Brinzolamide.

Conclusion: Altogether, our findings demonstrate that EVs size, surface membrane charge, and ionic strength of the surrounding have an impact on EVs:EVs interactions, which affect the uptake of NPCE EVs by TM cells.

Keywords: extracellular vesicles, trabecular meshwork, non-pigmented ciliary epithelium, primary open-angle glaucoma, zeta potential, ionic strength

\section{Introduction}

Eukaryotic and prokaryotic cells secrete a range of Extracellular Vesicles (EVs) of different sizes and content, among these are exosomes. ${ }^{1}$ Exosomes are small lipid bi-layer membranous vesicles sized 40-150 nm that allow exchange of nucleotides, proteins and lipids between cells. These extracellular nano-vesicles mediate cellular processes, including intracellular signaling. Such communication is not only essential for multicellular organisms but also is being increasingly recognized to play a role in the pathogenesis of diseases. ${ }^{2}$ Although in various works the use of the term "exosomes" is common we will use the term EVs, throughout the article. ${ }^{3}$

EVs can be characterized according to their physical properties, as size, concentration and surface charge, by applying several techniques ${ }^{4-8}$ that are used for size and concentration determination. The surface charge of EVs is reflected by the zeta potential (ZP). ${ }^{9}$ The ZP of disperse systems is a measure of charge stability and 
affects all particle-particle interactions ${ }^{10}$ and particlemedium interactions, including the tendency of the particles to aggregate. ${ }^{11} \mathrm{~A}$ higher absolute $\mathrm{ZP}$ results in greater electrostatic repulsions between particles and minimizes their tendency for aggregates formation. EVs with ZP between $-20 \mathrm{mV}$ and $+20 \mathrm{mV}$ tend to aggregate. In this context, differences in size and ZP values have been reported for characterized EVs derived from different body fluids, ${ }^{5,12-14}$ tissues $^{15,16}$ and cell cultures. ${ }^{17}$ Therefore, ZP is a useful tool to investigate the collective behavior of EVs in dispersed systems that allows studying the activity of EVs in biological processes. For example, the surface charge is known to influence various biological processes associated with EVs, such as cellular uptake. ${ }^{18}$ Like the plasma membrane of cells, EVs acquire a negative surface electrical charge when brought into contact with a hydrophilic buffer, phosphate-buffered saline (PBS), for instance. This means that a cluster induction of EVs by the elution buffer can take place. ${ }^{19}$ This data should be taken in consideration, since the stability and ability of EVs to deliver signals depend on the ZP of the EVs, the vehicle $\mathrm{pH}, \mathrm{EVs}$ concentration and on the ionic strength of the surrounding fluid that may be affected by disease condition and drugs treatments.

EVs are important constituents of the aqueous humor (AH), which participates in the communication between the non-pigmented ciliary epithelium (NPCE) and the trabecular meshwork (TM) tissue. ${ }^{20,21} \mathrm{AH}$ is produced by the NPCE and flows into the posterior chamber, which then moves into the anterior chamber and is finally drained through the TM and into Schlemm's canal. EVs mediated signaling in the ocular drainage system is under investigation regarding the pathophysiology of intraocular pressure that leads to primary open-angle glaucoma (POAG), characterized in deterioration of the optic nerve head. ${ }^{22}$ A potential pathway involved in the regulation of intraocular pressure and in the effects of NPCE-derived EVs on TM cells is the canonical Wnt signaling. The Wnt signaling pathway involves in the activation of Wnt target genes, leads to GSK3 $\beta$ inactivation by phosphorylation and stabilization of free $\beta$-Catenin. ${ }^{23,24}$ Experiments in our lab highlight the role of EVs in mediating signals between NPCE and TM cells, through the Wnt signaling pathway. ${ }^{25-27}$ In relation to the Wnt signaling, EVs can serve as transporters for aqueous insoluble ligands, such as lipophilic Wnt proteins. ${ }^{28,29}$

Regarding the impact of EVs concentration on signal transfer to target cells, we have examined the dosing effects of NPCE-derived EVs on TM Wnt signaling. A general dose response at the gene, matrix metalloproteinases activity and at the protein level of key canonical Wnt components was described. ${ }^{27}$ Concentrations of EVs were tested based on previous publications, taking into consideration some limitations. For example, there is a wide range of EVs amount per cell documented in the literature, ${ }^{30-33}$ and there is a lack of evidence regarding the physiological concentrations of EVs, which can vary from one system to the other depending on tissue and cell types, in malady or normal state. ${ }^{9}$ Our data support the concept that EVs biological effects are concentrationdependent at their target site. This led us to assume that higher EVs concentration will increase the chance for physical interactions between EVs to take place, which will eventually yield clusters. This kind of EVs interactions can take place not only among particles originated at the same cell but also between EVs secreted from different cell types.

Diverse internalization pathways might affect the kinetics of intracellular complex processing. Intercellular communication can be achieved by EVs membrane proteins that interact with the target cells through endocytosis, phagocytosis $^{33-38}$ or act as ligands for cell surface receptors on the target cell. ${ }^{2}$ Recently we were able to show that NPCE EVs uptake by TM cells is mediated through NPCE EVs surface proteins in an active manner that involves endocytosis and phagocytosis mechanism. ${ }^{63}$ Inhibitor and co-localization study ${ }^{39}$ revealed that the mechanism by which particles in sizes of 50-1000 nm internalized to the target cell was strongly dependent on particle size. Internalization of microspheres with a diameter of $50 \mathrm{~nm}$ and $100 \mathrm{~nm}$ involved clathrin-coated pits, whereas the internalization of the $200 \mathrm{~nm}$ and $500 \mathrm{~nm}$ beads was reduced by approx. $8-10$ times. Hence, size might be an important parameter in the pathway of EVs entry to target cells.

To determine what are the appropriate conditions for EVs physical interactions to occur, the following questions were taken into consideration; do the versatile concentrations and especially the high ones lead to aggregates formation? If so, what are the conditions that promote this clustering formation? Another important question is whether TM cells release EVs to physically interact with NPCE EVs, forming aggregates that attenuate incoming EVs mediated signaling in TM cells? Do eye drops for glaucoma treatment affect EVs surface charge that 
stimulates or attenuates the entry to the target site, ie, the TM cell?

Several publications suggest that EVs physically interact to form dimers or larger clusters to regulate signaling in biological systems. ${ }^{11,40}$ However, the relevance of aggregates formation and their effect on signal transfer to the target cells has not been explored yet, despite their crucial role in stability, pharmacokinetics, and release mechanism that are essential topics for developing drug delivery applications.

The main aim of the present study was to investigate the effect of interactions between NPCE and TM-derived EVs and aggregates formation on the entry to TM cells. To accomplish that, buffer solutions with several ionic strengths and various commercial solutions for POAG treatment, pure active ingredients, and preservative were examined. Then, fluorescently labeled NPCE EVs exposed to the solutions described above were incubated with TM cells at various time points, to track their internalization ratio.

\section{Methods \\ Cell Culture}

Cells were cultured according to previously published conditions. $^{25-27}$ Briefly, a human trabecular meshwork (TM) cell line was donated by Alcon Laboratories, Fort Worth, TX, USA and maintained in Dulbecco's modified Eagle's medium (DMEM) containing 10\% fetal bovine serum (FBS), $2 \mathrm{mM}$ L-glutamine, $100 \mu \mathrm{g} / \mathrm{mL}$ streptomycin and 100 units $/ \mathrm{mL}$ penicillin (all from Biological Industries, Kibbutz Beit Ha-Emek, Israel) in a humidified atmosphere of $95 \%$ air and $5 \% \mathrm{CO}_{2}$ at $37^{\circ} \mathrm{C}$. Human nonpigmented ciliary epithelial (NPCE) cell line ${ }^{41}$ was kindly supplied by Prof. Miguel Coca-Prados, Yale University, USA. Two different TM cell line splits (TM-10 and TM16) and a human NPCE (ODM-2) cell line were used along the study and cell lines authentication test was performed at the Genomics Center of Biomedical Core Facility, Technion, Israel, using the Promega GenePrint 24 System and the results are attached (Appendix A-I and $\mathrm{A}-\mathrm{II})$. All cell lines were used up to 25 passages.

The use of the human cell lines used in the present research was approved by the ethics committee of the BenGurion University of the Negev.

One hundred percent cells confluence was used through the studies. NPCE cells were cultured in DMEM depleted of FBS-derived EVs by overnight centrifugation, using Beckman Coulter ultracentrifugation, for $14 \mathrm{hr}, 4^{\circ} \mathrm{C}$ and $100,000 \times \mathrm{g}$. Two hundred milliliters of supernatant were collected and transferred to a $200 \mathrm{~mL}$ medium; containing $2 \mathrm{mM}$ L-glutamine, $0.1 \mathrm{mg} / \mathrm{mL}$ streptomycin, and 100 units/mL of penicillin. EVs depleted serum was used along all experiments.

\section{Research Model}

To evaluate the ionic strength effects on EVs size and ZP, the following solutions were analyzed; several PBS buffer strengths $(0.01 \mathrm{M}, 0.1 \mathrm{M}$, and $1 \mathrm{M})$, eye drops solutions used for POAG treatment; Alphagan-P ${ }^{\circledR}$ (Allergan), V-OPTIC $^{\circledR} \quad$ (Vitamed, Israel), AZOPT $^{\circledR} \quad$ (Alcon), Lumigan $^{\circledR}$ (Allergan) and Travatan ${ }^{\circledR}$ (Alcon). In addition, the pure active ingredients: Timolol maleate (SigmaAldrich), Brinzolamide (Cayman chemical company) or their preservative Benzalkonium chloride (BAK) (SigmaAldrich). Before the experiments, NPCE and TM-derived EVs were extracted by precipitation method. Their size and concentration were determined using TRPS technology. Then, sizes, ZP, and ionic strengths of EVs in various solutions were analyzed by NTA and Zeta sizer, respectively. After determination of the optimal conditions that favor EVs aggregates formation, we investigated whether EVs aggregates have an impact on their uptake by TM cells. To do so, labeled NPCE EVs were treated with several PBS concentrations or with various drugs, and incubated with TM cells for $30 \mathrm{~min}, 1 \mathrm{hr}, 2 \mathrm{hr}$, and $4 \mathrm{hr}$. Uptake of EVs by TM cells was analyzed using Flow Cytometer.

\section{EVs Extraction}

EVs were extracted from NPCE or TM cells using polyEthylene glycol (PEG) 8000 precipitation ${ }^{42-45}$ with slight modifications; cell culture conditioned medium was collected, centrifuged at $1500 \times \mathrm{g}$ for $15 \mathrm{~min}$ at $4^{\circ} \mathrm{C}$, to pellet dead cells and cell debris. Precipitation solution was prepared as follows: $100 \%$ PEG-8000, $1 \mathrm{M} \mathrm{NaCl}$, mixed with the conditioned medium $1: 5 \mathrm{v} / \mathrm{v}$, respectively, filtered through a $0.22 \mu \mathrm{m}$ PVDF filter and incubated overnight at $4^{\circ} \mathrm{C}$. The mixtures were centrifuged at $1500 \times \mathrm{g}$ at $4^{\circ} \mathrm{C}$ for $30 \mathrm{~min}$ to pellet the EVs. The pellet containing the EVs was re-suspended in $\mathrm{PBS} 0.1 \mathrm{M}, \mathrm{pH}=7.2$ and pelleted by ultracentrifugation at $100,000 \times \mathrm{g}$ for $70 \mathrm{~min}$ at $4^{\circ} \mathrm{C}$. The final pelleted EVs were suspended in $1 \mathrm{~mL}$ PBS $0.1 \mathrm{M}$, $\mathrm{pH}=7.2$ and were stored at $-80^{\circ} \mathrm{C}$ until use. 


\section{Tunable Resistive Pulse Sensing (TRPS)}

EVs size and concentration were determined by qNano (Izon Science, Christchurch, New Zealand) instrument, using the Tunable Resistive Pulse Sensing (TRPS) technology with an NP150 membrane $(85-300 \mathrm{~nm}) .{ }^{46}$ To eliminate contaminating debris, EVs samples were passed through $0.22 \mu \mathrm{m}$ filters before TRPS analysis. The apparatus was operated at a voltage of $0.48-0.64 \mathrm{~V}$ without pressure. The membrane was stretched to $47 \mathrm{~mm}$. Polystyrene beads at a concentration of $1.2 \times 10^{13}$ beads/ $\mathrm{mL}$ (110 nm; Izon Science) were used to calibrate size and concentration, following the manufacturer's instructions. Samples were diluted 100 -fold with PBS $0.1 \mathrm{M}$ buffer,

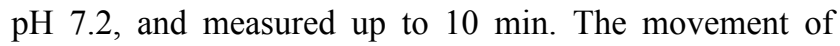
the particle through the membrane is identified as change in the ionic stream causing current changes. The signal power is proportional to the particle size. According to the number of particles and their velocity at a specific time, the qNano determines the EVs sizes and concentration.

\section{Zeta Potential and lonic Strength}

Following exposure of EVs to various conditions, ZP and ionic strength of both NPCE and TM derived EVs were analyzed to track physical interactions resulting in EVs aggregates. Measurements were performed using Nano Zeta sizer (Malvern). All experiments were performed at 1:1000 dilutions, yielding particle concentrations of $10.8 \times 10^{7} / \mathrm{mL}$ PBS. The effect of PBS concentrations $(0.01 \mathrm{M}, 0.1 \mathrm{M}$ and $1 \mathrm{M})$, various ocular drops for glaucoma treatment $(300 \mathrm{nM}$ Alphagan- $\mathrm{P}^{\circledR 47} \quad 3.4 \times 10^{3} \mathrm{nM} \quad$ V-Optic $^{\circledR, 48} \quad 1.3 \times 10^{3} \mathrm{nM}$ Azopt $^{\circledR, 49} 3.09 \mathrm{nM}$ Lumigan $^{\circledR}$ and $\left.3.91 \mathrm{nM} \operatorname{Travatan}^{\circledR}\right),{ }^{50}$ two active ingredients (Timolol maleate ${ }^{48}$ and Brinzolamide $^{49}$ ) and the main preservative present in the eye solutions - BAK, ${ }^{51}$ were examined. ZP and ionic strength for each treatment (PBS dilutions, eye drops, active ingredients or preservative) were determined for three EVs populations: NPCE EVs, TM EVs or NPCE EVs + TM EVs. In addition, we tested the effect of PBS dilutions on various combinations of EVs types at 1:1, 1:2, 2:1 NPCE:TM ratio. NPCE or TMderived EVs and their mixture of $1 *$ NPCE: $1 *$ TM suspended in $0.1 \mathrm{M}$ PBS, were used as controls in all experiments.

\section{Vesicles Characterization by NanoSight NS300}

Nanoparticle Tracking Analysis (NTA) was performed with a NanoSight NS300 instrument (Malvern) and the NTA 3.2 analytical software. Sample size distributions were calibrated in a liquid solution by the analysis of Brownian motion via light scattering. NTA provides single particle size and concentration measurements. All measurements were conducted at $25^{\circ} \mathrm{C}$. The same samples used for ZP and ionic strength measurements were utilized for NTA analysis to characterize the effect of PBS dilutions, eye drops for glaucoma treatment, their preservative and the effect of active ingredients on the size of EVs derived from NPCE and TM cells. Since the NP150 membrane used in qNano measurements has pores that allow the passage of particles with a diameter of $85-300 \mathrm{~nm}$, we chose to use the NTA device, to ensure that the entire particle range in the sample was analyzed, especially particles larger than $300 \mathrm{~nm}$ indicating aggregate formation.

\section{EVs Labeling}

Purified NPCE EVs were labeled with $2 \mathrm{mM}$ of DiD; a lipophilic fluorescent dye (1,10-dioctadecyl- 3,3,30,30tetramethyl-indodi-carbocyanine,4-chloro-benzenesulfonate salt Biotium, Hayward, CA, USA) at concentration of $10 \mu \mathrm{L} /$ $1 \mathrm{~mL}$ PBS (0.1M, pH 7.2). EVs were incubated for $10 \mathrm{~min}$ at room temperature to ensure uniform labeling. After staining, labeled EVs were resuspended in PBS and pelleted by ultracentrifugation at $100,000 \times \mathrm{g}$ for $70 \mathrm{~min}$ at $4^{\circ} \mathrm{C}$ to remove the unincorporated dye. The final labeled-EVs pellet was suspended in an appropriate volume of PBS (0.1M, pH 7.2), calculated by the final concentration of EVs that was incubated with TM cells $\left(5.4 \times 10^{9} \mathrm{EVs} / 2 \times 10^{6} \mathrm{TM}\right.$ cells $){ }^{27}$

\section{Flow Cytometry Analysis (FACS)}

To examine whether NPCE EVs aggregates have an impact on their uptake by TM cells, FACS analysis was used. TM cells were seeded in 6-well plates at a density of $0.5 \times 10^{6}$ cells per well in $6 \mathrm{~mL}$ of $10 \%$ DMEM. After cells reached $100 \%$ confluence, the medium was replaced with EVs depleted medium. Then, labeled NPCE EVs treated with various solutions for glaucoma treatment, or their preservative or the active ingredient, were incubated with TM cells for $30 \mathrm{~min}, 1 \mathrm{hr}, 2 \mathrm{hr}$ and $4 \mathrm{hr}$. TM cells were detached by trypsinization (Trypsin EDTA solution B $(0.25 \%)$, EDTA (0.05\%), (Biological Industrials)), washed once with EVs free medium and twice with PBS by centrifugation of $600 \mathrm{xg}$ for $5 \mathrm{~min}$ at $25^{\circ} \mathrm{C}$, for each wash. TM cells containing labeled EVs were re-suspended in $200 \mu \mathrm{L}$ of the washing buffer (1 mM EDTA, 2\% FBS, 0.01M PBS). Samples were filtered through FALCON tubes (Cell Strain $35 \mu \mathrm{M}$ W/5ML Tube-500/C, BactLab Israel) and fluorescence intensity was determined by Gallios Flow Cytometer (Beckman Coulter) 
using $638 \mathrm{~nm}$ Red laser (FL-6), for labeled EVs uptake assessment. Analysis was conducted using Kaluza software (Beckman Coulter).

\section{Statistics}

Data are presented as mean \pm standard deviation. Statistical evaluation of one-way ANOVA was performed with GraphPad Prism version 7.0 software (La Jolla, CA, USA). Differences between groups were tested using Tukey's test. Two-way ANOVA was conducted to determine NPCE EVs and TM EVs ZP, ionic strength and size to track EVs: EVs interactions using Zeta sizer and NTA devices. All tests were considered significant at $\mathrm{P}<0.05$.

\section{Results}

\section{EVs Sizes and Concentrations Measured by TRPS}

Size and concentrations of EVs isolated from NPCE or TM cells culture supernatants were measured using TRPS method prior to farther experiments. EVs concentration of $10.8 \times 10^{7}$ particles/mL was used for ZP, ionic strength and size determinations. For FACS analysis we used NPCE EVs concentration of $5.4 \times 10^{9}$ particles $/ \mathrm{mL}$. EVs size measurements resulted in $97.50 \pm 10.21 \mathrm{~nm}$ and $112.38 \pm 15.62 \mathrm{~nm}$ for NPCE (Figure 1A) and TM (Figure 1B) derived EVs, respectively.

\section{Zeta Potentials and Size of EVs Suspended in PBS with Different lonic Strengths}

Zeta sizer and NTA devices were used to measure the ZP, ionic strengths and diameter of three EVs groups (NPCE

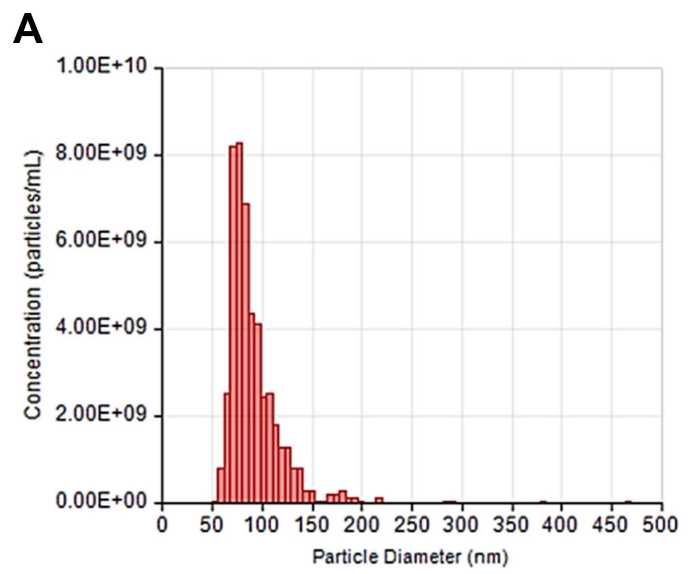

EVs, TM EVs, NPCE EVs +TM EVs) suspended in several concentrations of PBS buffers $(0.01 \mathrm{M}, 0.1 \mathrm{M}$, and $1 \mathrm{M})$. Increasing the ionic strength of the EVs buffers with the same $\mathrm{pH}$ (7.2), resulted with higher EVs size, higher ionic strength and less negative value of $\mathrm{ZP}$.

There was a significant change in ZP of TM EVs suspended in $0.01 \mathrm{M}$ PBS (Table 1, sector II) compare to NPCE EVs + TM EVs suspended in PBS with the same ionic strength (Table 1, sector III). Comparison of mode values that represent the EVs diameter, indicates that at $0.01 \mathrm{M}$ or $0.1 \mathrm{M}$ PBS concentrations, NPCE EVs size (Table 1, sector I) was significantly lower than TM EVs size (Table 1, sector II). The size of suspended NPCE EVs in $1 \mathrm{M}$ (Table 1 , sector I) was significantly lower than TM EVs (Table 1, sector II) and NPCE EVs + TM EVs (Table 1, sector III) exposed to the same PBS concentration.

\section{Size Distribution of NPCE/TM/NPCE +TM - Derived EVs Suspended in PBS with Various lonic Strengths}

Examination of the effect of phosphate buffer (PBS; $\mathrm{pH}$ 7.2) with various ionic strengths on EVs size distribution was done using NTA (Figure 2A-C). The size of NPCE EVs (red line) in several concentrations of buffer - $0.01 \mathrm{M}$, $0.1 \mathrm{M}$ and $1 \mathrm{M}$ was $90 \mathrm{~nm}$ (Figure 2A), $100 \mathrm{~nm}$ (Figure 2B) and $120 \mathrm{~nm}$ (Figure 2C) respectively, while TM EVs size (blue line) in the same PBS dilutions was $110 \mathrm{~nm}$ (Figure 2A), $120 \mathrm{~nm}$ (Figure 2B) and $150 \mathrm{~nm}$ (Figure 2C), respectively. TM EVs have a larger diameter than NPCE's EVs. The higher the ionic strength, the greater elevation in EVs size of both cell types (Figure $2 \mathrm{~A}-\mathrm{C}$ ). The same trend of increase in size, with increased PBS buffer concentration

B

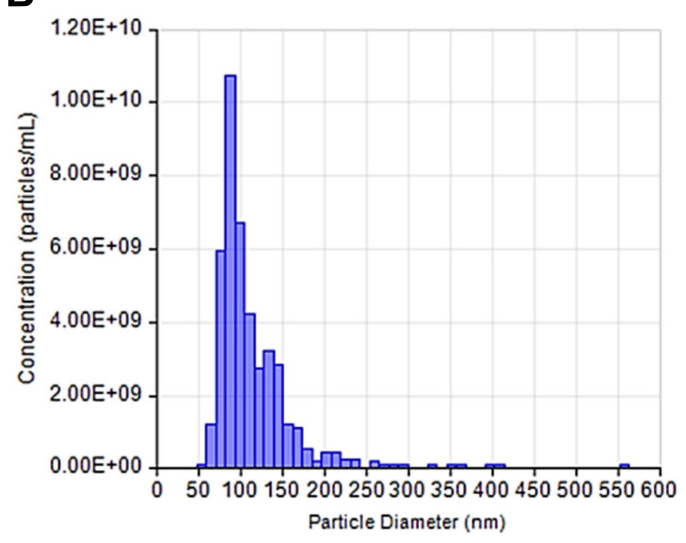

Figure I NPCE and TM Size and concentration.

Notes: Size and concentration distribution of NPCE (A) and TM (B) derived EVs as measured by Tunable Resistive Pulse Sensing Technology (TRPS). 
Table I Zeta Potentials and Size of EVs Suspended in PBS with Different lonic Strengths

\begin{tabular}{|c|c|c|c|c|}
\hline \multicolumn{5}{|c|}{ NPCE EVs } \\
\hline Sector & Measured Parameter & Z Potential (mV) & lonic Strength $(\mathrm{mS} / \mathrm{cm})$ & Mode (nm) \\
\hline I & $\begin{array}{l}0.0 I M \text { Control } \\
0.0 I M+\text { NPCE EVs } \\
0.1 M \text { Control } \\
0.1 M+\text { NPCE EVs } \\
\text { IM Control } \\
\text { IM + NPCE EVs }\end{array}$ & $\begin{array}{l}\text { NA } \\
-35.41 \pm 10.25 \\
\text { NA } \\
-12.27 \pm 3.15 \\
\text { NA } \\
-4.24 \pm 1.56\end{array}$ & $\begin{array}{l}3.2 \pm 0.29 \\
2.29 \pm 1.1 \\
13.76 \pm 0.49 \\
17.28 \pm 0.9 \\
59.49 \pm 4.92 \\
116.07 \pm \mid 1.57\end{array}$ & $\begin{array}{l}\text { NA } \\
86.93 \pm 4.67^{\dagger} \\
\text { NA } \\
98.47 \pm 5.21^{\ldots} \\
\text { NA } \\
109.2 \pm 7.43^{\$}\end{array}$ \\
\hline \multicolumn{5}{|c|}{ TM EVs } \\
\hline & Measured Parameter & Z Potential (mV) & lonic Strength $(\mathrm{mS} / \mathrm{cm})$ & Mode (nm) \\
\hline II & $\begin{array}{l}0.0 I M \text { Control } \\
0.0 I M+\text { TM EVs } \\
0.1 M \text { Control } \\
0.1 M+\text { TM EVs } \\
\text { IM Control } \\
\text { IM + TM EVs }\end{array}$ & $\begin{array}{l}\text { NA } \\
-33.28 \pm 9.06 * * \\
\text { NA } \\
-10.91 \pm 3.29 \\
\text { NA } \\
-4.82 \pm 1.78\end{array}$ & $\begin{array}{l}3.2 \pm 0.29 \\
2.4 \pm 0.37 * * * \\
13.76 \pm 0.49 \\
17.12 \pm 1.04 \\
59.49 \pm 4.92 \\
114.37 \pm 15.99\end{array}$ & $\begin{array}{l}\text { NA } \\
109.63 \pm 8.76 \\
\text { NA } \\
115.46 \pm 8.67 \\
\text { NA } \\
137.9 \pm 6.68\end{array}$ \\
\hline \multicolumn{5}{|c|}{ NPCE EVs + TM EVs } \\
\hline & Measured Parameter & Z Potential (mV) & lonic Strength $(\mathrm{mS} / \mathrm{cm})$ & Mode (nm) \\
\hline III & $\begin{array}{l}0.0 I M \text { Control } \\
0.0 I M+\text { NPCE EVs+ TM EVs } \\
0.1 M \text { Control } \\
0 . I M+\text { NPCE EVs + TM EVs } \\
\text { IM Control } \\
\text { IM + NPCE EVs + TM EVs }\end{array}$ & $\begin{array}{l}\text { NA } \\
-40.77 \pm 7.91 \\
\text { NA } \\
-11.35 \pm 2.08 \\
\text { NA } \\
-3.81 \pm 2.26\end{array}$ & $\begin{array}{l}3.2 \pm 0.29 \\
3.37 \pm 1.18 \\
13.76 \pm 0.49 \\
17.43 \pm 0.7 \\
59.49 \pm 4.92 \\
114.67 \pm 6.45\end{array}$ & $\begin{array}{l}\text { NA } \\
95.97 \pm 9.77 \\
\text { NA } \\
106.13 \pm 3.38 \\
\text { NA } \\
148.63 \pm 6.99\end{array}$ \\
\hline
\end{tabular}

Notes: Phosphate buffers with various ionic strengths were used to measure the NPCE EVs, TM EVs and NPCE EVs + TM EVs surface charge (ZP) and size (nm). ZP was measured with Nano Z Sizer in three independent triplicates and ten technical repetitions for each sample. EVs mode was measured by NTA in three independent triplicates and five technical repetitions for each sample. One-way ANOVA and Tukey's posttest were used to determine statistical difference. Significant differences among treatments

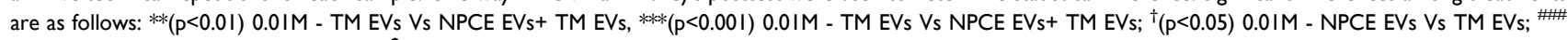
$(p<0.00 I) 0.1 M$ - NPCE EVs Vs TM EVs; ${ }^{\$}(p<0.0 I)$ IM - NPCE EVs Vs TM EVs, NPCE EVs Vs NPCE EVs+ TM EVs.

was found when NPCE EVs and TM EVs were suspended at a ratio of $1: 1$. Incubation of $1 * \mathrm{NPCE}$ EVs: $1 * \mathrm{TM}$ EVs (green line) with $0.01 \mathrm{M}, 0.1 \mathrm{M}$ and $1 \mathrm{M}$ PBS solutions led to particle size of $100 \mathrm{~nm}$ (Figure 2A), $110 \mathrm{~nm}$ (Figure 2B) and $150 \mathrm{~nm}$ (Figure 2C), respectively. Figure 2 indicates that for all three ionic strengths of PBS, NPCE EVs peak was shifted to the left compared to TM EVs peak and compared to $1 * \mathrm{NPCE}$ EVs: $1 * \mathrm{TM}$ EVs peak. The sizes obtained for $1 * \mathrm{NPCE}$ EVs: $1 * \mathrm{TM}$ EVs added to PBS in concentrations of $0.01 \mathrm{M}$ and $0.1 \mathrm{M}$ are the arithmetic means of NPCE EVs and TM EVs in the same ionic strengths solutions. At a concentration of $1 \mathrm{M}$ PBS, the size distribution of the EVs mixture ( 1 *NPCE EVs: $1 * \mathrm{TM}$ EVs) was more affected by TM EVs size than that of NPCE EVs. EVs size was affected by the ionic strength of the surrounding rather than EVs type in all mixtures. All samples that contained different EVs types and ratios showed a greater shift in size using $1 \mathrm{M}$ compared to $0.1 \mathrm{M}$ that is used routinely in labs as the ultimate buffer for maintaining EVs properties.

\section{Zeta Potentials and Size of NPCE or TM-Derived EVs Suspended in Different Solutions Used for Glaucoma Treatment and Their Main Preservative}

ZP, ionic strengths and size of NPCE or TM-derived EVs suspended with eye drops for glaucoma treatment or their pure active ingredient or their preservative were analyzed using Nano Zeta sizer and NTA devices. To reach the concentrations of the eye drops present in the $\mathrm{AH},{ }^{47-50}$ solutions were diluted using PBS buffer of 0.1M. Each solution belongs to one of the main groups for POAG treatment: Alphagan- $\mathrm{P}^{\circledR}-\alpha$ agonist, V-Optic ${ }^{\circledR \circledR}-\beta$ blocker, Azopt ${ }^{\circledR \circledR}-$ 
A

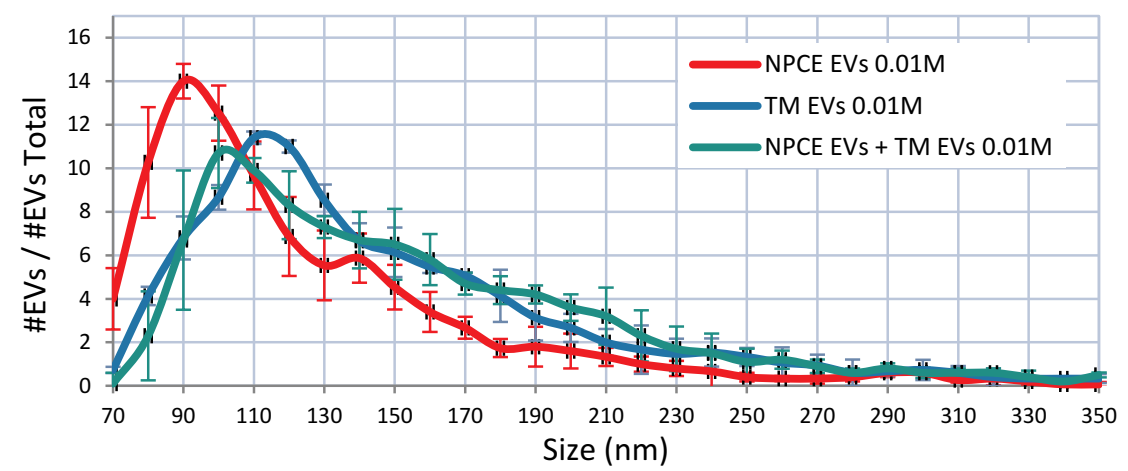

B

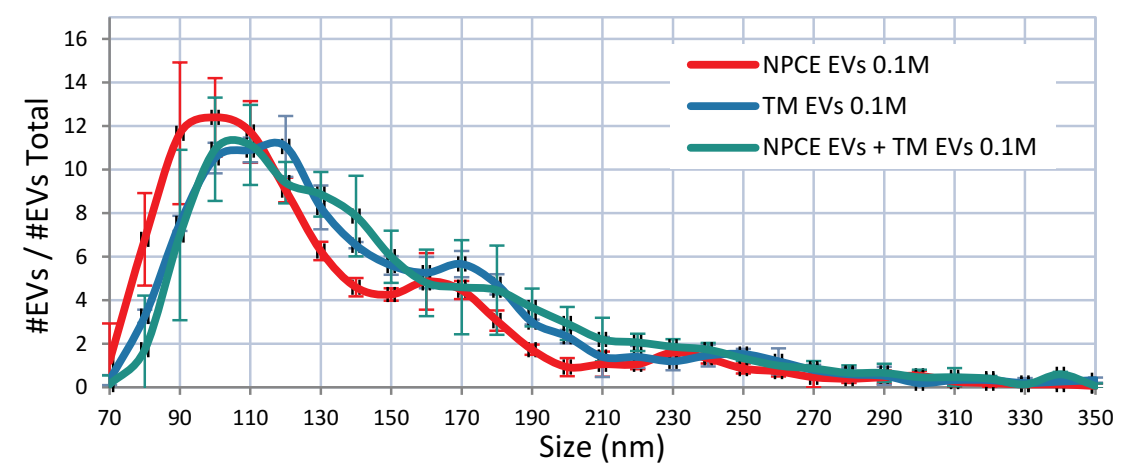

C

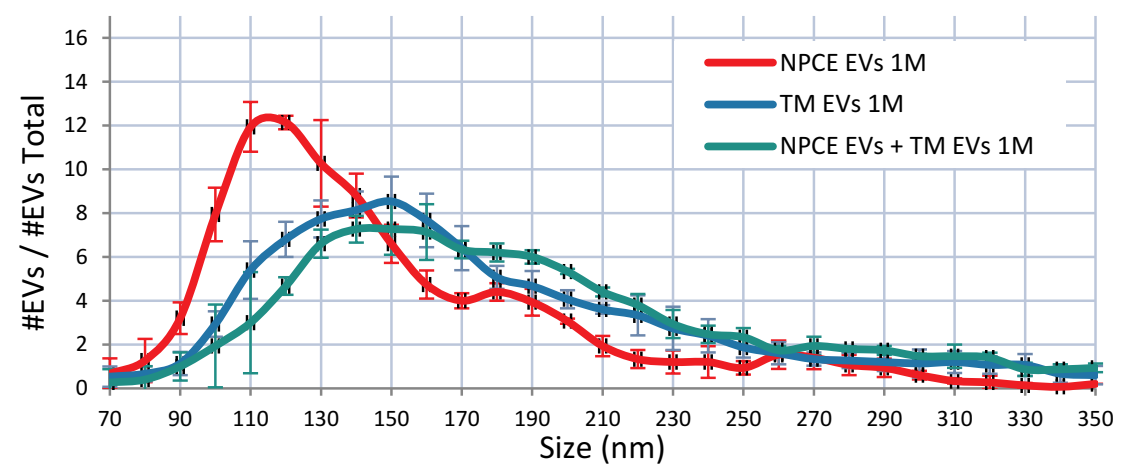

Figure 2 Size Distribution of NPCE/TM/NPCE+TM - Derived EVs Suspended in PBS with Different lonic Strengths.

Notes: NTA analysis of EVs size distribution as function of cell type and PBS ( $\mathrm{pH}=7.2$ ) dilutions. EVs were incubated with $0.0 \mathrm{IM}(\mathbf{A}), 0.1 \mathrm{M}$ (B) and IM (C) PBS prior analysis. Each histogram represents the frequency of EVs in a particular size, ranging from 70 to $350 \mathrm{~nm}$. Each line, red (NPCE EVs), blue (TM EVs) or green (NPCE EVs + TM $E V s)$, represents the mean \pm S.D. from three independent experiments performed in triplicates.

Carbonic anhydrase inhibitor, Lumigan ${ }^{\circledR}$ and Travatan ${ }^{\circledR}$ Prostaglandin analog. ZP of NPCE EVs (Table 2A) and TM EVs (Table $2 \mathrm{~B}$ ) were significantly less negative $(* * \mathrm{p}<0.01$, $* * * p<0.01$ for NPCE EVs and TM EVs, respectively) than the ZP of Azopt ${ }^{\circledR \circledR}$. Brinzolamide and Timolol maleate did not differ in their ZP compared to those of NPCE EVs (Table 2A) and TM EVs (Table 2B). The ZP of NPCE EVs (Table 2A) and TM EVs (Table 2B) were significantly more negative $(* * * \mathrm{p}<0.001)$ than the $\mathrm{ZP}$ of $\mathrm{V}-\mathrm{Optic}{ }^{\circledR \circledR}$ and BAK. Comparison of the eye drops Vs active ingredient alone and its preservative alone showed that the $\mathrm{ZP}$ of treated NPCE EVs (Table 2A) and TM EVs (Table 2B) with Azopt ${ }^{\circledR \circledR}$ were significantly more negative than the ZP of treated NPCE EVs or TM EVs with Brinzolamide and BAK $(* * * p<0.001)$. The ZP of NPCE EVs treated with V-Optic $^{\circledR}$ (Table 2A) was significantly less negative than Timolol maleate $(* * * \mathrm{p}<0.01)$, while TM EVs treated with V-Optic ${ }^{\circledR}$ showed no difference compared to Timolol maleate (Table 2B). No difference was found in ZP values of treated NPCE EVs (Table 2A) or TM EVs (Table 2B) with 
Table 2 Zeta Potentials and Size of NPCE or TM-Derived EVs Suspended in Different Solutions Used for Glaucoma Treatment and Their Main Preservative

\begin{tabular}{|c|c|c|c|}
\hline \multicolumn{4}{|c|}{$\begin{array}{l}\text { A) ZP, lonic Strength and Size of NPCE EVs Suspended in Different Solutions Used for Glaucoma Treatment Comparison. } \\
\text { Different Superscript Letters are Significantly Different from Each Other as Established by One-Way ANOVA and Tukey's } \\
\text { Posttest at Least at p<0.05. Results Represent the Mean } \pm \text { S.D from Three Independent Experiments Performed in Triplicates }\end{array}$} \\
\hline NPCE EVs + Treatment & Z Potential (mV) & lonic Strength $(\mathrm{mS} / \mathrm{cm})$ & Mode (nm) \\
\hline NPCE EVs (Untreated) & $-12.27 \pm 3.15^{\mathbf{a}}$ & $17.28 \pm 0.9^{\mathrm{a}}$ & $98.47 \pm 5.21^{\mathrm{a}}$ \\
\hline Azopt $^{\circledR}$ & $-14.94 \pm 1.72^{b}$ & $16.32 \pm\left. 0.8\right|^{b}$ & $95.24 \pm 4.88^{\mathrm{a}}$ \\
\hline Brinzolamide & $-\mid 1.71 \pm 2.94^{\mathrm{a}, \mathrm{c}}$ & $18.47 \pm 0.94^{c}$ & $95.1 \pm 6.18^{\mathrm{a}}$ \\
\hline V-Optic ${ }^{\circledR}$ & $-7.48 \pm 1.27^{\mathrm{d}, \mathrm{e}, \mathrm{f}}$ & $16.62 \pm 0.8^{a, b}$ & $100.59 \pm 5.68^{\mathrm{a}}$ \\
\hline Timolol maleate & $-10.65 \pm 2.54^{a, c, g}$ & $16.22 \pm 0.95^{\mathrm{a}}$ & $98.13 \pm 6.4^{a}$ \\
\hline BAK & $-8.77 \pm 2.1^{\mathrm{d}, \mathrm{g}}$ & $14.3 \pm 1.45^{\mathrm{d}}$ & $105.83 \pm 10.22^{a}$ \\
\hline Alphagan-P ${ }^{\circledR}$ & $-10.95 \pm 3.98^{h}$ & $|6.48 \pm 0.7|^{a, b}$ & $99.8 \pm 2.23^{\mathrm{a}}$ \\
\hline Lumigan $^{\circledR}$ & $-6.15 \pm 1.2^{\mathbf{j}}$ & $|7.1 \pm 0.8|^{\mathrm{a}}$ & $99.17 \pm 8.1^{\mathbf{a}}$ \\
\hline $\operatorname{Travatan}^{\circledR}$ & $-5.45 \pm 1.33^{j}$ & $16.94 \pm 0.93^{a, b}$ & $96.7 \pm 1.87^{a}$ \\
\hline \multicolumn{4}{|c|}{$\begin{array}{l}\text { B) ZP, lonic Strength and Size of TM EVs Suspended in Different Solutions Used for Glaucoma Treatment Comparison. Different } \\
\text { Superscript Letters are Significantly Different from Each Other as Established by One-Way ANOVA and Tukey's Posttest at } \\
\text { Least at } p<0.05 \text {. Results Represent the Mean } \pm \text { S.D from Three Independent Experiments Performed in Triplicates }\end{array}$} \\
\hline TM EVs + Treatment & Z Potential (mV) & lonic Strength $(\mathrm{mS} / \mathrm{cm})$ & Mode (nm) \\
\hline TM EVs (Untreated) & $-10.91 \pm 3.29^{a}$ & $17.12 \pm 1.04^{\mathrm{a}}$ & $115.46 \pm 8.67^{\mathrm{a}}$ \\
\hline Azopt $^{\circledR}$ & $-14.66 \pm 1.52^{b}$ & $16.21 \pm 0.85^{b}$ & $107.27 \pm 5.79^{a}$ \\
\hline Brinzolamide & $-10.96 \pm 1.33^{\mathbf{a}}$ & $17.17 \pm 0.75^{b}$ & $116.6 \pm 3.08^{\mathrm{a}}$ \\
\hline V-Optic ${ }^{\circledR}$ & $-6.79 \pm 1.61^{c}$ & $16.65 \pm 0.85^{a, b}$ & $107.17 \pm 9.21^{\mathrm{a}}$ \\
\hline Timolol maleate & $-8.93 \pm 4.36^{\mathrm{a}, \mathrm{c}}$ & $17.25 \pm 0.49^{a}$ & $112.43 \pm 15.6^{\mathbf{a}}$ \\
\hline BAK & $-8.1 \pm 3.42^{c}$ & $13.64 \pm 1.33^{c}$ & $113.13 \pm 11.11^{\mathrm{a}}$ \\
\hline Alphagan- $\mathbf{P}^{\circledR}$ & $-5.6 \pm 1.65^{d}$ & $16.44 \pm 0.83^{a, b}$ & $110.47 \pm 12.37^{a}$ \\
\hline Lumigan $^{\circledR}$ & $-6.3 \pm 1.9^{c, d}$ & $17 \pm 0.9^{a}$ & $102.67 \pm 2.84^{\mathrm{a}}$ \\
\hline $\operatorname{Travatan}^{\circledR}$ & $-6.72 \pm 1.66^{c, d}$ & $16.69 \pm 0.9^{a, b}$ & $109.23 \pm 1.5^{\mathrm{a}}$ \\
\hline
\end{tabular}

V-Optic ${ }^{\circledR(}$ and BAK. The ionic strengths of BAK for both NPCE EVs (Table 2A) and TM EVs (Table 2B) were significantly lower compared to control groups and all other solutions $(* * * p<0.001)$. For all treatments, no difference in size of NPCE EVs was found (Table $2 \mathrm{~A}$ and $\mathrm{B}$ ).

\section{Zeta Potentials of NPCE or TM - Derived EVs Suspended in Different Glaucoma Eye Drops and Their Main Preservative}

We further focused on the effect of V-Optic ${ }^{\circledR}$ and Azopt ${ }^{\circledR}$ solutions on the ZP of NPCE and TM-derived EVs. NPCE or TM-derived EVs, suspended in 0.1M PBS (pH 7.2) were used as controls. The ZP of EVs exposed to BAK was examined, to determine its contribution to changes in the EVs ionic strength. Timolol maleate and Brinzolamide, which are the active ingredients of V-Optic ${ }^{\circledR}$ and AZOPT ${ }^{\circledR}$, respectively, were tested. As shown in Figure $3 \mathrm{C}$ and $\mathrm{D}$ compared to control groups, the $\mathrm{ZP}$ of EVs exposed to V-Optic ${ }^{\circledR}(* * * \mathrm{p}<0.001)$, and BAK $(* * * \mathrm{p}<0.001, * * \mathrm{p}<0.01)$ were less negative. While the ZP of EVs exposed to Azopt ${ }^{\circledR}$ was more negative $(* * * p<0.001)$ (Figure $3 \mathrm{~A}$ and B). NPCE or TM EVs exposed to Brinzolamide had similar ZP as the control (Figure $3 \mathrm{~A}$ and $\mathrm{B}$ ), but less negative than Azopt ${ }^{\circledR}$ $(* * * p<0.001)$ and more negative than BAK $(* * * p<0.001)$. Timolol maleate exhibited no change in the ZP of TM EVs compared to the control group and V-Optic ${ }^{\circledR}$ values (Figure 3D). The ZP of NPCE EVs exposed to Timolol maleate (Figure $3 \mathrm{C}$ ) was significantly less negative than the control group $(* \mathrm{p}<0.05)$, but more negative than $\mathrm{V}$-Optic ${ }^{\circledR}$ $(* * * \mathrm{p}<0.001)$ and BAK $(* \mathrm{p}<0.05)$.

\section{Size Distribution of NPCE/TM - Derived EVs Suspended in Different Solutions Used for Glaucoma Treatment and Their Main Preservative}

We examined the effect of the ionic strength induced by various types of eye drops, their active ingredient and their 


\section{A}

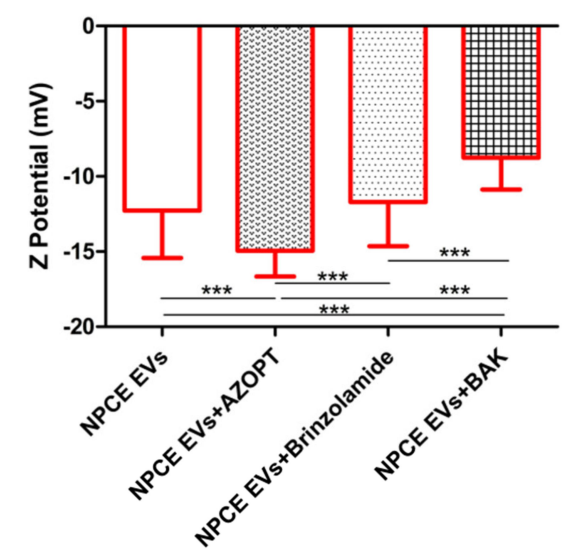

C

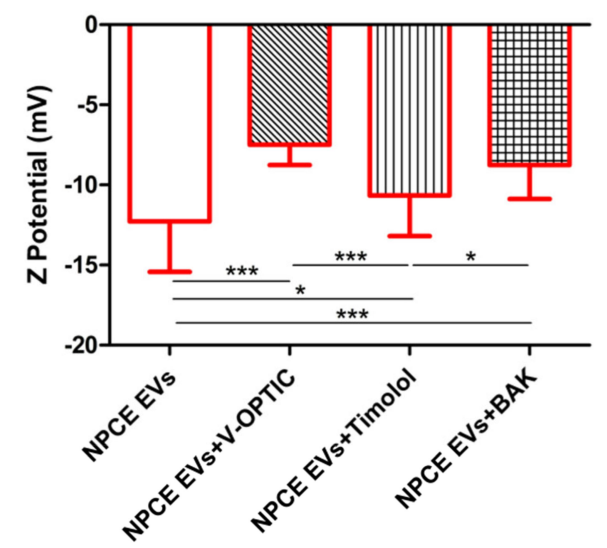

B

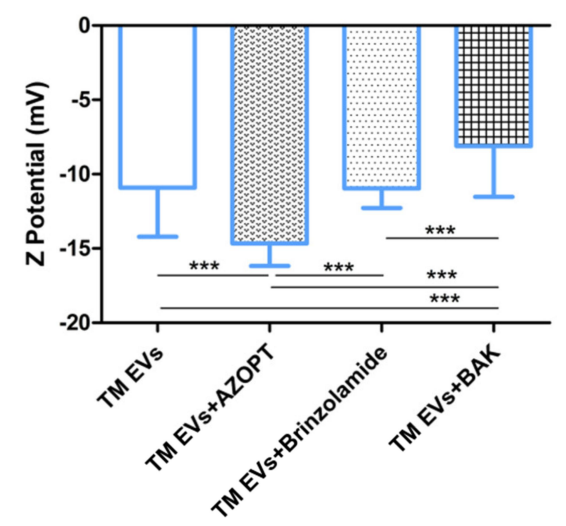

D

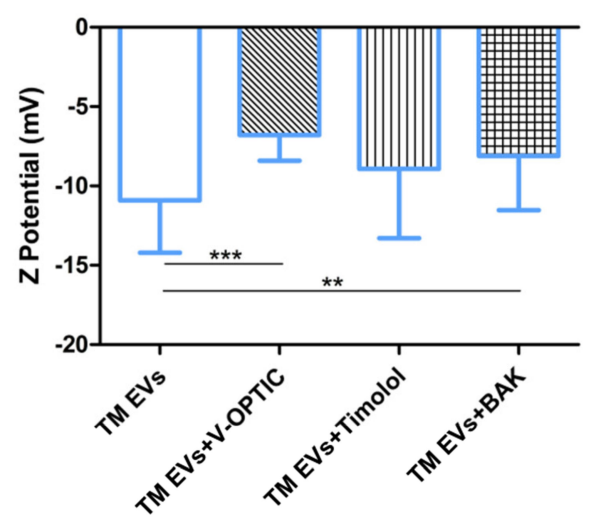

Figure 3 Zeta Potentials of NPCE or TM - Derived EVs Suspended in Different Glaucoma eye drops and their Main Preservative.

Notes: ZP of NPCE (A and C) or TM (B and D) derived EVs treated with different solutions used for glaucoma treatment, their active ingredients and preservative. Significant differences in the ZP of treated or untreated NPCE EVs $(\mathbf{A})$ and TM EVs (B) were demonstrated when exposed to Azopt ${ }^{\circledR}$, Brinzolamide or BAK. Treatment with V-Optic ${ }^{\circledR}$, Timolol maleate or BAK led to significant differences in the ZP of NPCE EVs (C) and TM EVs (D). The bar graph represents the means \pm S.D. from three independent experiments performed in triplicates. One-way ANOVA and Tukey's posttest were used to determine statistical difference, as indicated by asterisks (*P < 0.05 , $* * \mathrm{P}<0.01$, $* * * \mathrm{P}<0.001)$

main preservative on the size of NPCE and TM-derived EVs. The size of NPCE or TM-derived EVs (with the same concentration and $\mathrm{pH}$ of 7.2) was measured with NTA. For all experiments and EVs cell types, no significant difference in EVs size was detected. An average size of 90-120 nm was documented for NPCE EVs, TM EVs and combination of both populations in the ratio of $1: 1$. Nevertheless, a possible potential formation EVs aggregates following extraction, storing and dilutions for size analysis was detected as shown in Figure 4. Figure 4A and $\mathrm{C}$ demonstrate that the size of NPCE EVs suspended with BAK (gray line) was larger than the control of untreated NPCE EVs (red line). The size of TM EVs exposed to Azopt $^{\circledR}$ (green line - Figure 4 and B) or Timolol maleate (purple line - Figure 4D) was smaller than the control of untreated TM EVs (blue line).

\section{Labeled NPCE EVs Uptake by TM Cells Following Exposure to Different Glaucoma Eye Drops and Their Main Preservative}

The surface charge of the EVs is reflected by its ZP and may affect the interactions with the target cell surface. EVs may internalize by cells in many machineries, including receptor-mediated endocytosis, phagocytosis, lipid rafts machinery, micro-pinocytosis, or direct fusion with the target cell membrane. ${ }^{52,53}$ Some of these routes involve membrane fusion or recognition of EVs surface proteins by the target cell. ${ }^{38}$ Hence, changes in the ZP and ionic strength may reflect on the preferred mechanism of uptake.

The changes observed in the ZP and ionic strengths of EVs (Table 2, Figure 3) led us to investigate the effect of glaucoma eye drops, their active ingredients and 
A

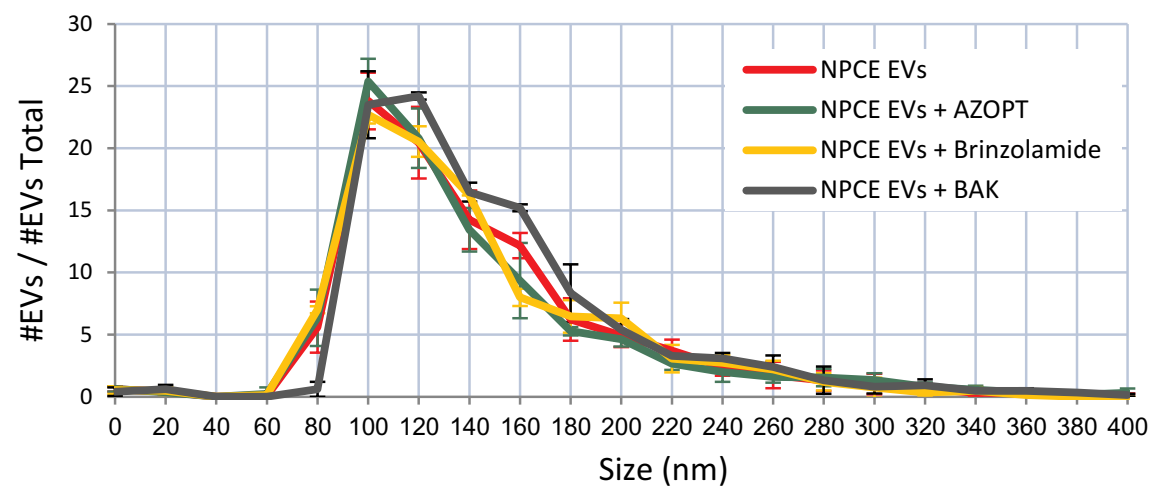

B

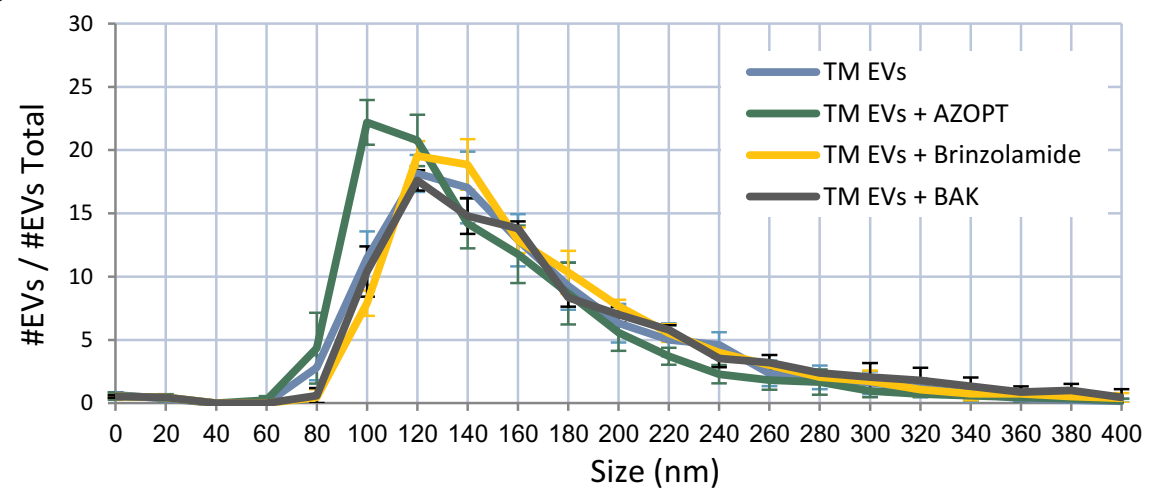

C

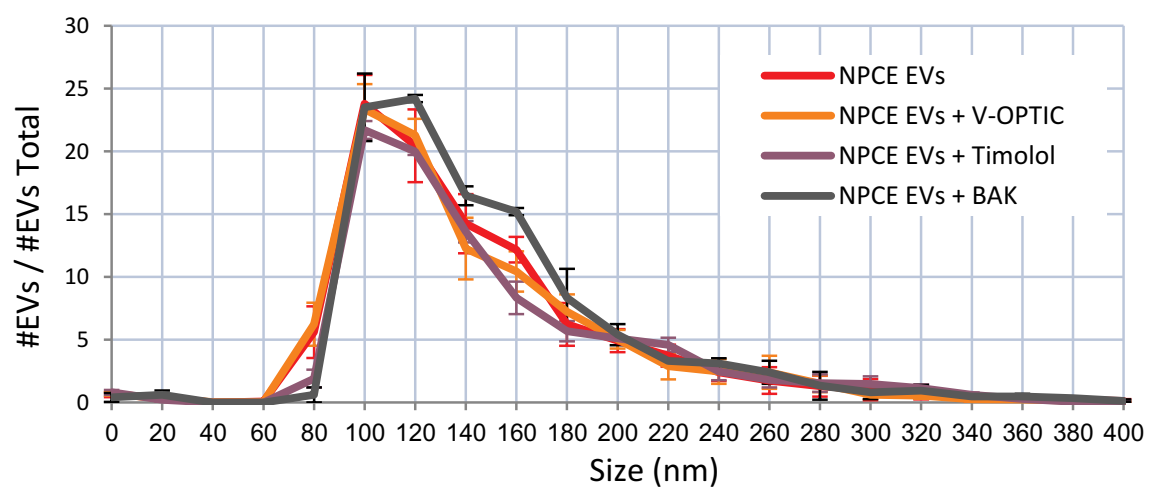

D

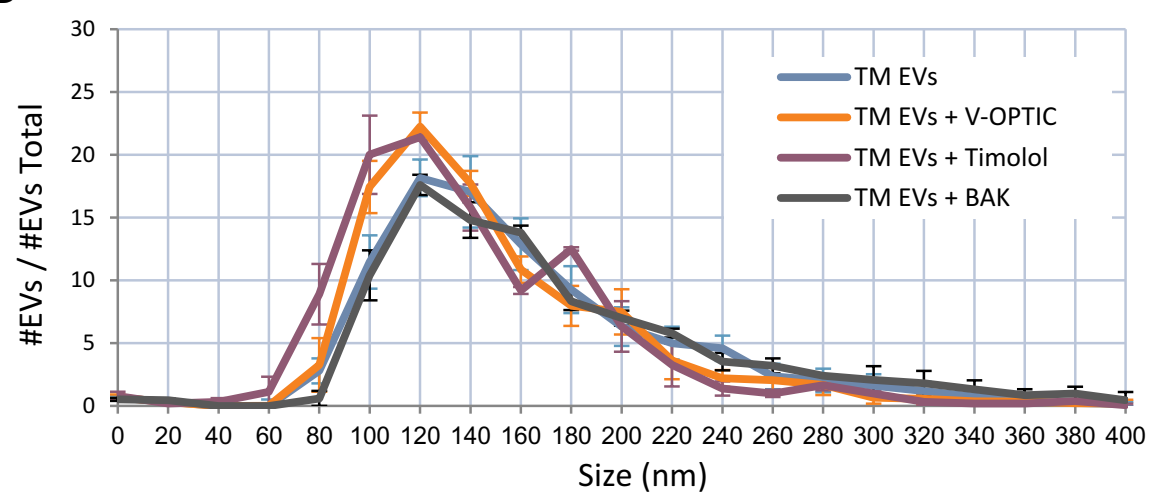

Figure 4 Size Distribution of NPCE/TM - Derived EVs Suspended in Various Solutions used for Glaucoma Treatment and their Main Preservative.

Notes: Size distribution of NPCEEVs $(\mathbf{A}$ and $\mathbf{C})$ or TMEVs $(\mathbf{B}$ and $\mathbf{D})$ suspended with Azopt ${ }^{\circledR}$, Brinzolamide and BAK $\left(\mathbf{A}\right.$ and B) or V-Optic ${ }^{\circledR}$, Timolol maleate and BAK $(\mathbf{C}$ and $\mathbf{D})$ as measured by NTA. Each histogram represents the frequency of EVs in a particular size, ranging from 0 to $400 \mathrm{~nm}$. Means \pm S.D. from three independent experiments performed in triplicates are presented. 
preservative on NPCE EVs internalization to TM cells. TM cells were incubated with DID labeled NPCE EVs exposed to various treatments for $30 \mathrm{~min}, 1 \mathrm{hr}, 2 \mathrm{hr}$ and $4 \mathrm{hr}$ at $37^{\circ} \mathrm{C}$ (Figure 5). A significant effect of NPCE EVs uptake was observed after $30 \mathrm{~min}$ (Figure 5B, I) compared to other time points. Treatment with Azopt ${ }^{\circledR}$ exhibited a significant elevation in NPCE EVs uptake compared to untreated and labeled NPCE EVs - at $30 \mathrm{~min}(* * \mathrm{P}<0.01)$ (Figure 5B, I), $1 \mathrm{hr}(* * * \mathrm{P}<0.001)$ (Figure 5B, II) and $2 \mathrm{hr}$ $(* * * \mathrm{P}<0.001)$ (Figure 5B, III). Elevation in EVs uptake was also established by BAK after 30 min of incubation $(* * \mathrm{p}<0.01)$ (Figure 5B, I). A reduction in NPCE EVs uptake by TM cells was mediated by V-Optic ${ }^{\circledR}$, Timolol maleate and Brinzolamide (Figure 5B), while the two last ones caused a significant effect at $30 \min (* * * p<0.001)$ (Figure 5B, I). For all time points, Timolol maleate significantly reduced the uptake by TM cells (Figure 5B). The significant effects shown after $30 \mathrm{~min}$ incubation with TM cells were not observed at the latest time points of $1 \mathrm{hr}, 2$ $\mathrm{hr}$ and $4 \mathrm{hr}$, except for NPCE EVs treated with Azopt ${ }^{\circledR}$ (Figure 5B, I-III) and Timolol maleate (Figure 5B, I-IV).

\section{Discussion}

The role of NPCE-derived EVs on the Wnt signal modulation in TM cells was previously demonstrated. ${ }^{25-27}$ Changes in Wnt proteins expression levels in TM cells as a result of NPCE-derived EVs can be a result of TM internalization process of the EVs, or TM surface ligand activation by EVs. There are various routes of EVs uptake, the main being endocytosis, phagocytosis and soluble or juxtacrine signaling. ${ }^{52}$ The feasibility of these mechanisms is also/partly mediated by the presence of specific proteins on the surface membrane of EVs. These surface proteins can be damaged by significant changes in solution $\mathrm{pH}$, ionic strength, temperature, and destructive enzymes. Hence, it is important to maintain the appropriate conditions of solutions for EVs actions and functions. ${ }^{40,54,55}$ Given the lack of knowledge whether eye drops for glaucoma treatment or $\mathrm{AH}$ surrounding may contribute to NPCE-TM communication mediated by EVs, it is difficult to define precisely whether EVs interactions occur selectively, based on the particle size, zeta potential and/or ligand-receptor pairs. This prompted us to investigate the effect of EVs size and surface charge mediated by several environmental conditions (buffer concentrations and the ionic strengths of drugs) on the efficiency of their cellular uptake as a function of time. This insight is of relevance in the context of defining EVs internalization pathways, and for the utilization of EVs as bio-therapeutics and drug delivery vehicles.

The present findings demonstrate the importance of the surrounding conditions, rather than particle type (Figure 1, Table 1). We found that the ratio of NPCE EVs: TM EVs have no major effect on EVs size and cluster formation (Figure 2). Increasing the ionic strength of the EVs buffers with the same $\mathrm{pH}$ (7.2) resulted in higher EVs size, higher ionic strength, and less negative value of zeta potential. This trend indicates that at a higher buffer concentration, the tendency for aggregate formation increases. A comparison of the zeta potentials at $0.01 \mathrm{M}$ indicates that the value of TM EVs was significantly less negative than that of NPCE EVs: TM EVs at a 1:1 ratio. This might suggest that the presence of NPCE EVs in a mixture can cause repulsion with TM EVs and decrease aggregates formation (Table 1, Figure 2). For all experiments and EVs cell types, no difference in EVs size was detected using various eye drops solutions or their preservative (Table 2). These results highlight the significant effect that $\mathrm{AH}$ surrounding composition and ionic strength may have on EVs size and aggregates formation in the ocular drainage system. Solution of NPCE EVs with Azopt ${ }^{\circledR}$, Brinzolamide, or BAK (Figure 3A) indicates that the active ingredient and the preservative contribute to the decrease in the zeta potential. The same conclusion can be drawn for TM EVs (Figure 3B). Moreover, the size of the TM EVs was decreased using Azopt ${ }^{\circledR}$ (Figure 4B), while the size of the NPCE EVs suspended in BAK was increased (Figure 4A). This suggests that additional non-active ingredients in AZOPT $^{\circledR}$ eye drops solution, such as Carbomer used as thickening agent ionized at $\mathrm{pH}=7.2$, might affect the EVs zeta potential to be more negative. It is known that the complex formation between the active ingredients in drugs and their non-active ingredients often leads to their stabilization. The forces involved are van der Waals forces, dipoledipole interactions, hydrogen bonding, Coulomb forces, and hydrophobic interactions. An example for such ingredient is Carbomer that improves the bioavailability of drugs and is widely employed in ophthalmic formulations. ${ }^{56}$ Carbomer is an acid-based polymer with $\mathrm{pKa}$ value of $6-6.5$ that has proton-able carboxylic groups linked to the molecular network of the polyelectrolyte, which allow interactions with oppositely charged drugs through the formation of a polyelectrolyte-drug complex. ${ }^{57}$ At $\mathrm{pH}$ of 7.2 phosphate buffer, the carboxylic groups are highly dissociated and the repulsion between the negatively charged carboxyl groups causes the molecules to uncoil into an elongated structure. ${ }^{58}$ In aqueous dispersions, the ionic-pair formation yields a high 

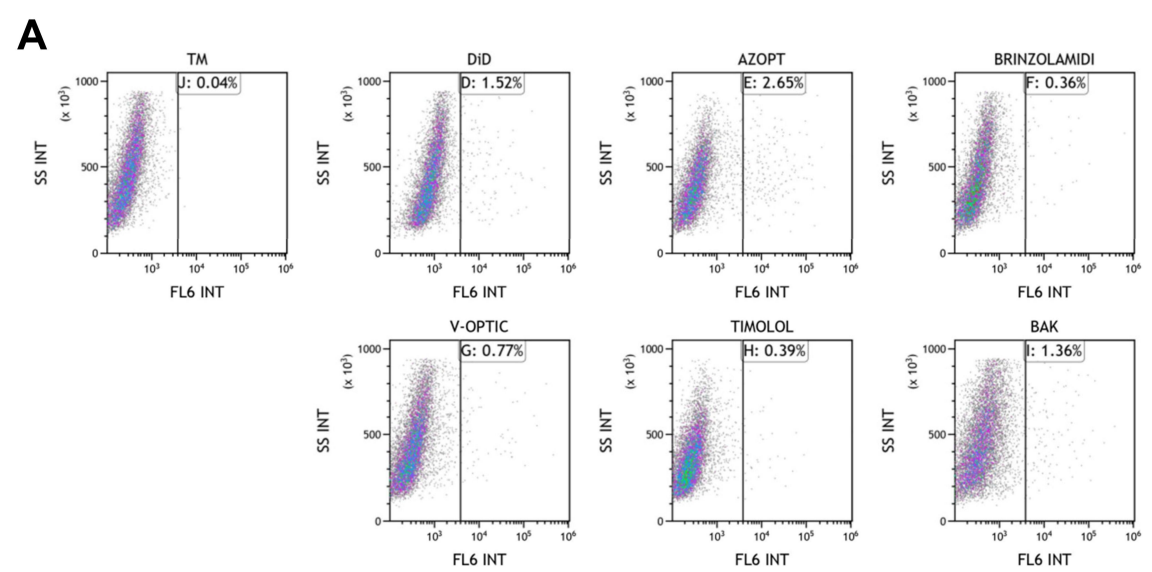

B

I.

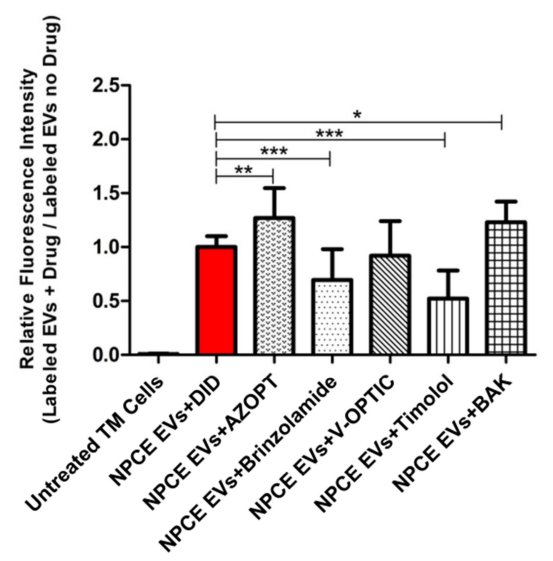

III.

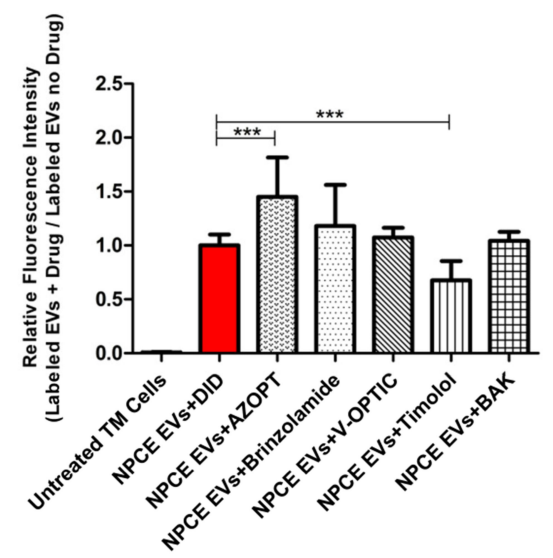

II.

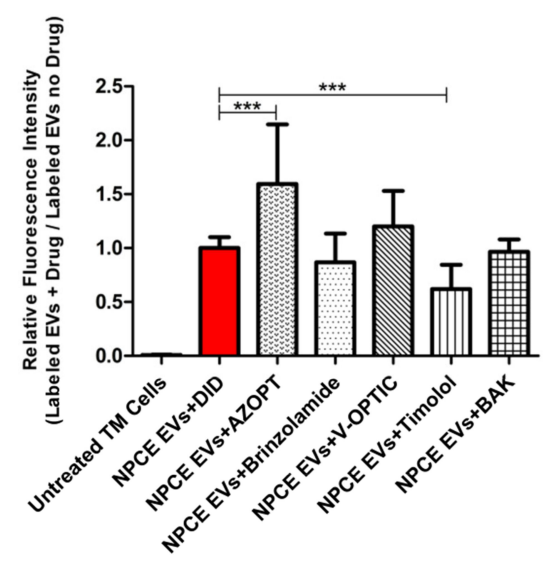

IV.

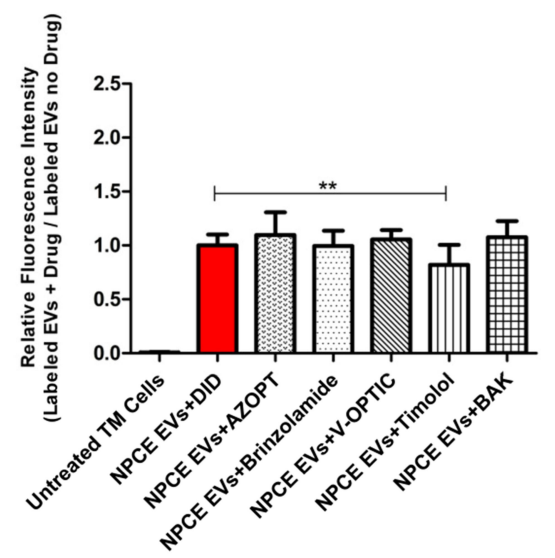

Figure 5 Labeled NPCE EVs Uptake by TM Cells Following Exposure to Different Glaucoma eye drops and their Main Preservative.

Notes: Effects of treated NPCE EVs incubated in various solutions for glaucoma treatment, their active ingredients and preservative on the uptake by TM cells. (A) Representative FACS plots, showing the percentage of TM cells positive to DID labeled treated NPCE EVs - right panel, compared to TM cells incubated with labeled and untreated NPCE EVs, after 30 min of incubation at $37^{\circ} \mathrm{C}$. (B) Evaluation of the uptake ratio of labeled NPCE EVs using FACS analysis, presented as relative fluorescence intensity of positive-gated TM cells. The bar graphs represent means \pm S.D. from three independent experiments performed in triplicates. One-way ANOVA and Tukey's posttest were used to determine statistical difference, as indicated by asterisks ( $* \mathrm{P}<0.05, * * \mathrm{P}<0.0 \mathrm{I}, * * * \mathrm{P}<0.00 \mathrm{I})$.

proportion of counter-ionic condensation with numerous various basic drugs, exhibiting both high-affinity constants and negative electro-kinetic potential. ${ }^{56}$ Figure $3 \mathrm{C}$ indicates that the active ingredient, Timolol maleate, contributed to the elevation in zeta potential that was detected for NPCE EVs treated with V-Optic ${ }^{\circledR}$, while BAK caused a decrease in the 
zeta potential. The same conclusion is relevant for TM EVs (Figure 3D), though only a trend was detected. It suggests that V-Optic ${ }^{\circledR}$ and Timolol maleate have more influence on NPCE EVs zeta potential than on TM EVs. As depicted in Figure 4: while the size of NPCE EVs exposed to BAK was sharply increased compared to NPCE EVs treated with V-Optic ${ }^{\circledR}$ or Timolol maleate (Figure $4 \mathrm{C}$ ), the trend was less noticeable for TM EVs treated with BAK. Nevertheless, the sizes of TM EVs exposed to V-Optic ${ }^{\circledR}$ or Timolol maleate were decreased compared to untreated TM EVs (Figure 4D).

The increase (more negative charged) in the zeta potential of NPCE EVs exposed to Azopt ${ }^{\circledR}$ (Table 2A, Figure $3 \mathrm{~A}$ ), explains the significant elevation in NPCE EVs uptake by TM cells after $30 \mathrm{~min}, 1 \mathrm{hr}$ and $2 \mathrm{hr}$ of incubation (Figure 5B, I-III). A significant decrease in the uptake of treated NPCE EVs with Timolol maleate (Figure 5B, IIV) or Brinzolamide (Figure 5B, I) can be explained by the decrease (less negative charged) in the zeta potentials (Table 2A, Figure 3A and C). Treatment with Timolol maleate caused a significant decrease in NPCE EVs uptake at all-time points, thus suggesting that for such an active ingredient the preferred mechanism of uptake may involve a longer process such as endocytosis or phagocytosis. Since the significant effect of NPCE EVs internalization was observed after $30 \mathrm{~min}$ (Figure 5A and B, I) compared to longer time points ( $1 \mathrm{hr}, 2 \mathrm{hr}$, and $4 \mathrm{hr}$ ), a ligandreceptor recognition is a possible mechanism of uptake.

Even though we did not find a change in size after incubation of NPCE EVs with TM EVs at different ratios $(1: 1,1: 2,2: 1)$, we cannot rule out the option that physical interactions between EVs have an inhibitory effect on incoming signals. Another possibility that needs further research is whether particles, probably with remarkable difference in their sizes, may fuse to create a larger particle (one "swollen" by another) and whether it has an influence on the surface antigen composition. An additional point to take in consideration is the diverse range of mechanisms that includes clathrin or caveolae-mediated endocytosis and is used by cells to accomplish different tasks. ${ }^{39}$ Caveolae are characterized by the presence of the integral membrane protein caveolin and can internalize large molecular complexes, such as cholera toxin, ${ }^{59}$ certain viruses such as SV40 (simian virus $40)^{60,61}$ and bacteria. ${ }^{62}$ It will be interesting to obtain an insight into the size-dependent regulation of particle internalization via an endocytic or a juxtacrine signaling mechanism. We have shown that eye drops for glaucoma treatment, not only affects the target site cells but also affects the entry of particles by changing their zeta potential. Therefore, it is important to examine the type and dose of eye drops given to the patient, as it may not only affect treatment efficacy but may cause changes in the signal transduction mediated by EVs. We are aware that the use of human TM cell line embodies a limitation for extrapolating our findings to primary TM cells, as phenotypic changes have been described for cell lines in general. However, our findings light up the principle that the effect of drugs on EVs ZP changes affect EVs subsequent uptake by TM and consequently determine EVS effects on TM function. As such, they contribute an innovative perspective that might be general and valid for other experimental models as well. Evaluating the validity in primary cells results will certainly reinforce the potential clinical significance of the present study.

Increased or decreased uptake of EVs into TM cells by IOP lowering drugs may affect biological processes in TM cells. Since EVs carry messages in the form of mRNA, miRNA and have been engineered to carry siRNA, we propose that the biological effects will depend on the load composition of the EVs. The excipients used in IOP lowering drugs and in other ocular preparations might have a significant contribution to their effect on EVs uptake so that the pharmaceutical composition of the preparation is also significant.

To summarize, our results suggest that particle size, surface membrane charge, and the ionic strength of the surrounding have an important role in NPCE-TM cell communication via EVs. The present work contributes to the recognition of the importance of interactions between nanoparticles used in drug delivery system.

\section{Acknowledgments}

We thank Doctor Valeria Feinstein and Mr. Yariv Greenshpan for technical support through the study. We also acknowledge the ISRAEL SCIENCE FOUNDATION (grant No. 1315/14). The sponsor or funding organization had no role in the research.

\section{Disclosure}

The authors report no conflicts of interest for this work.

\section{References}

1. Raposo G, Stahl PD. Extracellular vesicles: a new communication paradigm? Nat Rev Mol Cell Biol. 2019;20(9):509-510. doi:10.1038/ s41580-019-0158-7

2. Mathivanan S, Ji H, Simpson RJ. Exosomes: extracellular organelles important in intercellular communication. J Proteomics. 2010;73 (10):1907-1920. doi:10.1016/j.jprot.2010.06.006 
3. Witwer KW, Thery C. Extracellular vesicles or exosomes? On primacy, precision, and popularity influencing a choice of nomenclature. J Extracell Vesicles. 2019;8(1):1648167. doi:10.1080/20013078.2019.1648167

4. Zabeo D, Cvjetkovic A, Lasser C, Schorb M, Lotvall J, Hoog JL. Exosomes purified from a single cell type have diverse morphology. $J$ Extracell Vesicles. 2017;6(1):1329476. doi:10.1080/20013078.20 17.1329476

5. Pisitkun T, Shen RF, Knepper MA. Identification and proteomic profiling of exosomes in human urine. Proc Natl Acad Sci U S A. 2004;101(36):13368-13373. doi:10.1073/pnas.0403453101

6. van der Vlist EJ, Nolte-'t Hoen EN, Stoorvogel W, Arkesteijn GJ, Wauben MH. Fluorescent labeling of nano-sized vesicles released by cells and subsequent quantitative and qualitative analysis by high-resolution flow cytometry. Nat Protoc. 2012;7(7):1311-1326. doi:10.1038/nprot.2012.065

7. Gercel-Taylor C, Atay S, Tullis RH, Kesimer M, Taylor DD. Nanoparticle analysis of circulating cell-derived vesicles in ovarian cancer patients. Anal Biochem. 2012;428(1):44-53. doi:10.1016/j. ab.2012.06.004

8. Soo CY, Song Y, Zheng Y, et al. Nanoparticle tracking analysis monitors microvesicle and exosome secretion from immune cells. Immunology. 2012;136(2):192-197. doi:10.1111/j.1365-2567.2012.03569.x

9. Yu B, Zhang X, Li X. Exosomes derived from mesenchymal stem cells. Int J Mol Sci. 2014;15(3):4142-4157. doi:10.3390/ijms1503 4142

10. Hunter RJ. Zeta Potential in Colloid Science: Principles and Applications. Vol. 2. Academic press; 2013.

11. Midekessa G, Godakumara K, Ord J, et al. Zeta potential of extracellular vesicles: toward understanding the attributes that determine colloidal stability. ACS Omega. 2020;5:16701-16710. doi:10.1021/ acsomega.0c01582

12. Skog J, Würdinger T, Van Rijn S, et al. Glioblastoma microvesicles transport RNA and proteins that promote tumour growth and provide diagnostic biomarkers. Nat Cell Biol. 2008;10(12):1470-1476. doi: $10.1038 / \mathrm{ncb} 1800$

13. Runz S, Keller S, Rupp C, et al. Malignant ascites-derived exosomes of ovarian carcinoma patients contain CD24 and EpCAM. Gynecol Oncol. 2007;107(3):563-571. doi:10.1016/j.ygyno.2007.08.064

14. Lasser C, Alikhani VS, Ekstrom K, et al. Human saliva, plasma and breast milk exosomes contain RNA: uptake by macrophages. $J$ Transl Med. 2011;9:9. doi:10.1186/1479-5876-9-9

15. Phinney DG, Pittenger MF. Concise review: MSC-derived exosomes for cell-free therapy. Stem Cells. 2017;35(4):851-858. doi:10.1002/ stem. 2575

16. Budnik V, Ruiz-Canada C, Wendler F. Extracellular vesicles round off communication in the nervous system. Nat Rev Neurosci. 2016;17 (3):160-172. doi:10.1038/nrn.2015.29

17. Leblanc P, Arellano-Anaya ZE, Bernard E, et al. Isolation of exosomes and microvesicles from cell culture systems to study prion transmission. Methods Mol Biol. 2017;1545:153-176.

18. Frohlich E. The role of surface charge in cellular uptake and cytotoxicity of medical nanoparticles. Int J Nanomedicine. 2012;7:55 77-5591. doi:10.2147/IJN.S36111

19. Petersen KE, Manangon E, Hood JL, et al. A review of exosome separation techniques and characterization of B16-F10 mouse melanoma exosomes with AF4-UV-MALS-DLS-TEM. Anal Bioanal Chem. 2014;406(30):7855-7866. doi:10.1007/s00216-014-8040-0

20. Dismuke WM, Challa P, Navarro I, Stamer WD, Liu Y. Human aqueous humor exosomes. Exp Eye Res. 2015;132:73-77. doi:10.1016/j.exer.2015.01.019

21. Stamer WD, Hoffman EA, Luther JM, Hachey DL, Schey KL. Protein profile of exosomes from trabecular meshwork cells. J Proteomics. 2011;74(6):796-804. doi:10.1016/j.jprot.2011.02.024

22. Schmidl D, Schmetterer L, Garhofer G, Popa-Cherecheanu A. Pharmacotherapy of glaucoma. J Ocul Pharmacol Ther. 2015;31 (2):63-77. doi:10.1089/jop.2014.0067
23. Nelson WJ, Nusse R. Convergence of Wnt, beta-catenin, and cadherin pathways. Science. 2004;303(5663):1483-1487. doi:10.1126/ science. 1094291

24. Villarreal G, Chatterjee A, Oh SS, Oh DJ, Kang MH, Rhee DJ. Canonical wnt signaling regulates extracellular matrix expression in the trabecular meshwork. Invest Ophthalmol Vis Sci. 2014;55 (11):7433-7440. doi:10.1167/iovs.13-12652

25. Lerner N, Avissar S, Beit-Yannai E, Katoh M. Extracellular vesicles mediate signaling between the aqueous humor producing and draining cells in the ocular system. PLoS One. 2017;12(2):e0171153. doi:10.1371/journal.pone. 0171153

26. Lerner N, Schreiber-Avissar S, Beit-Yannai E. Extracellular vesicle-mediated crosstalk between NPCE cells and TM cells result in modulation of Wnt signalling pathway and ECM remodelling. J Cell Mol Med. 2020;24(8):4646-4658. doi:10.1111/jcmm.15129

27. Tabak S, Schreiber-Avissar S, Beit-Yannai E. Extracellular vesicles have variable dose-dependent effects on cultured draining cells in the eye. $J$ Cell Mol Med. 2018;22(3):1992-2000. doi:10.1111/jcmm.13505

28. Gross JC, Chaudhary V, Bartscherer K, Boutros M. Active Wnt proteins are secreted on exosomes. Nat Cell Biol. 2012;14 (10):1036-1045. doi:10.1038/ncb2574

29. Luga V, Zhang L, Viloria-Petit AM, et al. Exosomes mediate stromal mobilization of autocrine Wnt-PCP signaling in breast cancer cell migration. Cell. 2012;151(7):1542-1556. doi:10.1016/j.cell.2012.11.024

30. Li Y, Shen Z, Yu X-Y. Transport of microRNAs via exosomes. Nat Rev Cardiol. 2015;12(4):198. doi:10.1038/nrcardio.2014.207-c1

31. Ramteke A, Ting H, Agarwal C, et al. Exosomes secreted under hypoxia enhance invasiveness and stemness of prostate cancer cells by targeting adherens junction molecules. Mol Carcinog. 2015;54 (7):554-565. doi:10.1002/mc.22124

32. Safdar A, Saleem A, Tarnopolsky MA. The potential of endurance exercise-derived exosomes to treat metabolic diseases. Nat Rev Endocrinol. 2016;12(9):504-517. doi:10.1038/nrendo.2016.76

33. Tian T, Zhu Y-L, Zhou -Y-Y, et al. Exosome uptake through clathrin-mediated endocytosis and macropinocytosis and mediating miR-21 delivery. J Biol Chem. 2014;289(32):22258-22267. doi:10.10 74/jbc.M114.588046

34. Holder B, Jones T, Sancho Shimizu V, et al. Macrophage exosomes induce placental inflammatory cytokines: a novel mode of maternal-placental messaging. Traffic. 2016;17(2):168-178. doi:10. $1111 /$ tra. 12352

35. Nanbo A, Kawanishi E, Yoshida R, Yoshiyama H. Exosomes derived from Epstein-Barr virus-infected cells are internalized via caveola-dependent endocytosis and promote phenotypic modulation in target cells. J Virol. 2013;87(18):10334-10347. doi:10.1128/ JVI.01310-13

36. Carter GC, Bernstone L, Baskaran D, James W. HIV-1 infects macrophages by exploiting an endocytic route dependent on dynamin, Rac1 and Pak1. Virology. 2011;409(2):234-250. doi:10.1016/j.virol.2010.10.018

37. Feng D, Zhao WL, Ye YY, et al. Cellular internalization of exosomes occurs through phagocytosis. Traffic. 2010;11(5):675-687. doi:10.11 11/j.1600-0854.2010.01041.x

38. Mulcahy LA, Pink RC, Carter DR. Routes and mechanisms of extracellular vesicle uptake. $J$ Extracell Vesicles. 2014;3:24641. doi: $10.3402 /$ jev.v3.24641

39. Rejman J, Oberle V, Zuhorn IS, Hoekstra D. Size-dependent internalization of particles via the pathways of clathrin- and caveolae-mediated endocytosis. Biochem J. 2004;377(1):159-169. doi:10.1042/bj20031253

40. Beit-Yannai E, Tabak S, Stamer WD. Physical exosome: exosome interactions. J Cell Mol Med. 2018;22(3):2001-2006. doi:10.1111/ jcmm. 13479

41. Coca-Prados M, Escribano J. New perspectives in aqueous humor secretion and in glaucoma: the ciliary body as a multifunctional neuroendocrine gland. Prog Retin Eye Res. 2007;26(3):239-262. doi:10.1016/j.preteyeres.2007.01.002 
42. Ludwig AK, De Miroschedji K, Doeppner TR, et al. Precipitation with polyethylene glycol followed by washing and pelleting by ultracentrifugation enriches extracellular vesicles from tissue culture supernatants in small and large scales. J Extracell Vesicles. 2018;7 (1):1528109. doi:10.1080/20013078.2018.1528109

43. Rider MA, Hurwitz SN, Meckes DG. ExtraPEG: a polyethylene glycol-based method for enrichment of extracellular vesicles. Sci Rep. 2016;6:23978. doi:10.1038/srep23978

44. Lv CY, Ding WJ, Wang YL, et al. A PEG-based method for the isolation of urinary exosomes and its application in renal fibrosis diagnostics using cargo miR-29c and miR-21 analysis. Int Urol Nephrol. 2018;50(5):973-982. doi:10.1007/s11255-017-1779-4

45. Weng Y, Sui Z, Shan Y, et al. Effective isolation of exosomes with polyethylene glycol from cell culture supernatant for in-depth proteome profiling. Analyst. 2016;141(15):4640-4646. doi:10.1039/ C6AN00892E

46. Lobb RJ, Becker M, Wen SW, et al. Optimized exosome isolation protocol for cell culture supernatant and human plasma. $J$ Extracell Vesicles. 2015;4:27031. doi:10.3402/jev.v4.27031

47. Takamura Y, Tomomatsu T, Matsumura T, et al. Vitreous and aqueous concentrations of brimonidine following topical application of brimonidine tartrate $0.1 \%$ ophthalmic solution in humans. $J$ Ocul Pharmacol Ther. 2015;31(5):282-285. doi:10.1089/jop.2015.0003

48. Blanksma LJ. Concentration of timolol in aqueous humour. Doc Ophthalmol. 1991;78(3-4):255-258. doi:10.1007/BF00165688

49. Kadam RS, Jadhav G, Ogidigben M, Kompella UB. Ocular pharmacokinetics of dorzolamide and brinzolamide after single and multiple topical dosing: implications for effects on ocular blood flow. Drug Metab Dispos. 2011;39(9):1529-1537. doi:10.1124/dmd.111.040055

50. Faulkner R, Sharif NA, Orr S, et al. Aqueous humor concentrations of bimatoprost free acid, bimatoprost and travoprost free acid in cataract surgical patients administered multiple topical ocular doses of LUMIGAN or TRAVATAN. J Ocul Pharmacol Ther. 2010;26 (2):147-156. doi:10.1089/jop.2009.0098

51. Rasmussen CA, Kaufman PL, Kiland JA. Benzalkonium chloride and glaucoma. J Ocul Pharmacol Ther. 2014;30(2-3):163-169. doi:10.10 89/jop.2013.0174

52. McKelvey KJ, Powell KL, Ashton AW, Morris JM, McCracken SA. Exosomes: mechanisms of uptake. J Circ Biomark. 2015;4:7. doi: $10.5772 / 61186$
53. Franzen CA, Simms PE, Van Huis AF, Foreman KE, Kuo PC, Gupta GN. Characterization of uptake and internalization of exosomes by bladder cancer cells. Biomed Res Int. 2014;2014:1-11. doi:10.1155/2014/619829

54. Gangalum RK, Atanasov IC, Zhou ZH, Bhat SP. $\alpha$ B-crystallin is found in detergent-resistant membrane microdomains and is secreted via exosomes from human retinal pigment epithelial cells. $J$ Biol Chem. 2011;286(5):3261-3269. doi:10.1074/jbc.M110.160135

55. Lee HM, Choi EJ, Kim JH, et al. A membranous form of ICAM-1 on exosomes efficiently blocks leukocyte adhesion to activated endothelial cells. Biochem Biophys Res Commun. 2010;397(2):251-256. doi:10.1016/j.bbrc.2010.05.094

56. Zoppi A, Linck YG, Monti GA, et al. Studies of pilocarpine: carbomer intermolecular interactions. Int J Pharm. 2012;427(2):252-259. doi:10.1016/j.ijpharm.2012.02.005

57. Kaur G, Grewal J, Jyoti K, Jain UK, Chandra R, Madan J. Oral controlled and sustained drug delivery systems: concepts, advances, preclinical, and clinical status. In: Drug Targeting and Stimuli Sensitive Drug Delivery Systems. William Andrew Publishing, Elsevier; 2018:567-626.

58. Wen H, Park K. Oral Controlled Release Formulation Design and Drug Delivery: Theory to Practice. John Wiley \& Sons; 2011.

59. Lencer WI, Hirst TR, Holmes RK. Membrane traffic and the cellular uptake of cholera toxin. Biochimica et Biophysica Acta. 1999;1450 (3):177-190. doi:10.1016/S0167-4889(99)00070-1

60. Stang E, Kartenbeck J, Parton RG. Major histocompatibility complex class I molecules mediate association of SV40 with caveolae. Mol Biol Cell. 1997;8(1):47-57.

61. Anderson HA, Chen Y, Norkin LC. MHC class I molecules are enriched in caveolae but do not enter with simian virus 40. J Gen Virol. 1998;79(6):1469-1477. doi:10.1099/0022-1317-79-6-1469

62. Shin J-S, Abraham SN. Caveolae as portals of entry for microbes. Microbes Infect. 2001;3(9):755-761. doi:10.1016/S1286-4579(01) 01423-X

63. Tabak S, Hadad U, Schreiber-Avissar S, Beit-Yannai E. Non-pigmented ciliary epithelium derived extracellular vesicles uptake mechanism by the trabecular meshwork. FASEB J. 2020.
International Journal of Nanomedicine

\section{Publish your work in this journal}

The International Journal of Nanomedicine is an international, peerreviewed journal focusing on the application of nanotechnology in diagnostics, therapeutics, and drug delivery systems throughout the biomedical field. This journal is indexed on PubMed Central, MedLine, CAS, SciSearch ${ }^{\mathbb{R}}$, Current Contents ${ }^{\mathbb{B}} /$ Clinical Medicine,
Journal Citation Reports/Science Edition, EMBase, Scopus and the Elsevier Bibliographic databases. The manuscript management system is completely online and includes a very quick and fair peer-review system, which is all easy to use. Visit http://www.dovepress.com/ testimonials.php to read real quotes from published authors. 